\title{
Sodobna umetnost in državljanska vzgoja - vprašanje mogočih medpredmetnih povezav na vsebinski ravni
}

Metoda KemperL ${ }^{1}$

$\approx$ Sodobna umetnost se v primerjavi s predhodno moderno umetnostjo razlikuje $\mathrm{v}$ tem, da se spet vrača $\mathrm{k}$ družbi in vsakdanjemu življenju ter da tematizira aktualne težave, s katerimi se srečuje človek tukaj in zdaj. Zelo pogosta tema je trajnostni razvoj in s tem povezane vsebine, kot so: okoljevarstvo, vrednote, odnos do drugega itn. To so hkrati teme, ki sodijo v koncept aktivnega državljanstva, zato razumevanje sodobne umetnosti pravzaprav zahteva aktivno državljanstvo. Še posebej to velja za relacijsko umetnost, ki od gledalca zahteva aktivno participacijo $\mathrm{v}$ umetnini. V prispevku se sprašujem, kako uresničevati povezanost sodobne umetnosti in državljanske vzgoje v osnovni šoli. Sodobna pedagoška doktrina zelo spodbuja medpredmetno povezovanje, zato sem analizirala učna načrta predmetov likovna vzgoja ter državljanska in domovinska vzgoja ter etika in ugotovila, da sta s tega vidika težko povezljiva. Na odsotnost sodobne umetnosti v učnem načrtu za likovno vzgojo se sicer že dlje časa opozarja, a težava učnega načrta je konceptualne narave. Skupne cilje državljanske in likovne vzgoje je mogoče uresničevati $\mathrm{z}$ intenzivnejšim medinstitucionalnim povezovanjem šol z galerijami in muzeji, ki predstavljajo sodobno umetnost. Na treh primerih sodobnih umetnin, natančneje participatornih praks (Proletarier aller Länder, Žicar in EU/Others) pokažem na mogočo medpredmetno povezavo na vsebinski ravni in opozorim na s pedagoškega vidika pogosto spregledano dejstvo, da sodobno umetnost doživljamo tukaj in zdaj.

Ključne besede: sodobna umetnost, participatorne likovne prakse, državljanska vzgoja, likovna vzgoja, medpredmetne povezave

1 Univerza v Ljubljani, Pedagoška fakulteta, Slovenija metoda.kemperl@pef.uni-lj.si 


\section{Povezava državljanske vzgoje in likovne vzgoje}

Sodobna pedagoška doktrina spodbuja medpredmetno povezovanje, zato so tudi zadnja izhodišča za kurikularno prenovo od piscev posodobljenih učnih načrtov iz leta 2011 terjala, da medpredmetno povezovanje bolj poudarjajo. Posledično naj bi tudi šole oz. učitelji predmete med seboj povezovali, ekskurzije in izleti naj bi bili bolj interdisciplinarni in naj bi vključevali medpredmetna področja (Karba, 2008). Ena ključnih novosti vseh posodobitvenih učnih načrtov $\mathrm{v}$ osnovni šoli je medpredmetno povezovanje in kroskurikularne teme. Na to temo je bilo pri nas v zadnjem času napisanih tudi veliko člankov, ki se tičejo državljanske vzgoje, prevladujejo pa tisti, ki povezovanje vidijo s predmeti zgodovina, geografija in slovenščina (na primer Davies, 2003; Mihelj, 2003; Resnik Planinc 2003; Slater, 2003; Justin, 2003; Kunaver, 2006; Kostrevc, 2006; Devjak, 2007).

Politični filozof in teoretik državljanske vzgoje Will Kymlicka trdi, naj državljanska vzgoja ne bo izoliran sestavni del učnega programa, temveč eden izmed ciljev in načel, ki oblikuje celoten program (Kymlicka, 1999). Pri nas se v osnovni šoli najbolj udejanja pri predmetu državljanska in domovinska vzgoja ter etika (v nadaljevanju DDE). Nekateri teoretiki pri tem poudarjajo, naj bodo vsebine usmerjene na določene pojave $\mathrm{v}$ učenčevem okolju, naj bi povezovanje vodilo k globljemu razumevanju odnosov do resničnega sveta ali da naj več predmetov povežejo $\mathrm{v}$ aktiven projekt, $\mathrm{v}$ katerem bodo otroci videli povezave $\mathrm{z}$ vsakodnevnimi situacijami (Drake, 1998, str. 154; Štemberger, 2007, str. 96). Interdisciplinarne diskusije učencu omogočajo lažje izražanje lastnih idej in interpretacij ter spodbujajo podajanje različnih mnenj in vidikov (Hickman \& Kiss, 2010). Tako posredovano znanje je integrirano, se povezuje in spodbuja transfer vedenja in sposobnosti z enega področja na drugega. Hickmann in Kiss (2010) trdita, da bi z učenjem prenašanja znanja in spretnosti z enega na drugo področje učencem omogočili uporabnost in celovitejše ter globlje razumevanje snovi in učnih konceptov. V raziskavi iz leta 2010 sta avtorja ugotovila pozitivne povezave med interdisciplinarnim pristopi ter sposobnostjo transferja znanja in spretnosti. Rawding in Wall (1991) sta v kroskurikularni študiji izvedla poskus medpredmetnega poučevanja religije in umetnosti. V intervjujih s sodelujočimi učenci sta ugotovila, da so nekateri izmed njih odkrili ne le povezave med umetnostjo in verstvi, temveč so začeli integrirati vidike izkušenj in znanj onkraj okvirov šolskih predmetov. Torej učenci niso zgolj uspešno povezali tem dotičnih predmetov, ampak so se naučili koncepta medpredmetnega mišljenja na splošno in to znanje prenesli tudi na primere drugih predmetov in področij.

Ker se danes na vzgojo in izobraževanje gleda tudi kot na usposabljanje za življenje, ima likovna vzgoja v tem procesu pomembno mesto (Hickman, 2005). 
Glede na povedano imajo vsi posodobljeni učni načrti obveznih osnovnošolskih predmetov predlagano tudi medpredmetno povezovanje. Večina učnih načrtov ne navaja le predmetov, s katerimi je možno povezovanje, ampak tudi primere vsebin za medpredmetno povezovanje. Poleg tega so navedeni primeri vsebin in veščin za kroskurikularne dejavnosti tako na vertikalni kot na horizontalni ravni povezanosti.

Le dva izmed teh učnih načrtov (v nadaljevanju UN) ostajata le pri navedbi predmetov, s katerimi je možno povezovanje, in to sta predmeta DDE in likovna vzgoja (v nadaljevanju LV). Prvi ob navedenih UN poudarja, da naj bosta kulturna vzgoja in vzgoja za trajnostni razvoj osrednji sestavini predmetnega in medpredmetnega pristopa poučevanja ter da je medpredmetno povezovanje ključni pogoj za izvedbo celostnega pristopa (UV, DDE, 2011, str. 20, 21). Prav UN za LV pa je do konkretiziranja medpredmetnih povezav zelo zadržan.

Na prvi pogled se zdi to precej nenavadno, saj je umetnost že sama po sebi interdisciplinarna in zato kot nalašč za medpredmetno povezovanje, kot je to na primeru grške umetnosti pokazal T. Germ (2008, str. 43, 44). Pri vsaki poglobljeni interpretaciji umetnine je potreben interdisciplinaren pristop oz. mora biti razlaga umetniškega dela večplastna. Ali kot je zapisala že L. Tavčar, »/.../ poskušamo $\mathrm{v}$ umetnostnih muzejih in galerijah doseči, da mladi obiskovalci ogled umetniških del povežejo $\mathrm{z} \mathrm{v}$ šoli pridobljenimi znanji in predmeti, kot so: zgodovina, geografija, umetnostna zgodovina, književnost, glasba itd. Ogledi jim omogočijo, da ta znanja povežejo, ko pod vodstvom muzejskega pedagoga prodirajo v pomenske plasti umetniškega dela« (Tavčar, 2009, str. 78).

\section{Sodobna umetnost kot angažirana družbena praksa}

Umetnost je komunikativna in pomaga ljudem razumeti vidike sveta, ki jih sicer ne bi mogli razumeti. Je osrednja ter bistvena človeška in družbena aktivnost (Stibbs, 1998, str. 202; Freedman, 2003). Umetnost je družbena praksa, saj umetnik skozi umetniško delo izraža svoj odnos do sebe, odnos do drugih in odnos do sveta, v katerim živi, zato mora dobro razumeti družbeni ustroj, v katerem deluje (Bourriaud, 2007, str. 92). Tako je umetnost že sama po sebi povezana s konceptom državljanstva oz. bi morala postati del edukacije vsakega državljana, saj je vir znanja, prepričanj in vrednot o nas samih in o svetu (Dobbs, 1998, str. 9). S cilji državljanske vzgoje se povezuje, ker poglobljena obravnava umetnine, ki temelji na poststrukturalističnih metodah (Grierson, 2003, str. 102; Knight, 2010, str. 240, 241), nujno vsebuje kritično mišljenje ter oblikovanje stališč in vrednot. Poleg zgodovine, geografije in slovenščine je poznavanje evropske in slovenske umetnosti ključnega pomena za ustvarjanje in ohranjanje nacionalne identitete, 
kar je sestavina domovinske vzgoje. To je povezano tudi z multikulturnostjo, ki je prav tako ena temeljnih usmeritev vzgoje in izobraževanja, saj če ne poznamo in razumemo svoje kulture, težko vzpostavimo odnos do druge kulture in jo težje razumemo. Poznavanje umetnosti mnogih kultur pa pomaga razumeti ljudi teh kultur, ne samo njihovih umetniških del (Dobbs, 1998, str. 11). Obiskovanje muzejev, galerij in drugih javnih prostorov, kjer lahko doživljamo umetniška dela, je del angažiranega družbenega in socialnega delovanja, k čemur spodbuja državljanska vzgoja. To je v Sloveniji še toliko bolj pomembno, saj so pri nas take ustanove pretežno financirane iz javnega denarja in aktivnega državljana bi moralo zanimati, kakšne aktivnosti finančno podpira. Zato bi moralo biti navajanje na obiskovanje muzejev obvezni del osnovnošolskega kurikuluma. Na ta način bi se, kot opozarjata Halstead in Pike (2006, str. 66), otroke kot bodoče davkoplačevalce navajalo na uporabljanje tistega, kar bodo plačevali, in bodo do tega, kar plačujejo, tudi vzpostavili kritičen odnos. Namreč, pravita avtorja, če državljani ne čutijo potrebe po produkciji umetniških del, je lahko delovanje takih institucij finančno ogroženo (Halstead \& Pike, 2006, str. 66). Muzeji na splošno s svojo razstavno politiko oblikujejo vrednote, ker pa so te dejavnosti pri nas financirane iz državne blagajne, bi sklepali, da se država sprašuje, katere vrednote preko muzejev javnih družbenih institucij podpira. ${ }^{2}$

Na umetnost se je že od nekdaj gledalo tudi kot na del in kot sredstvo vzgoje in izobraževanja oz. kot del dolgoročnega spreminjanja našega vedênja in obnašanja (Vigotski, 1975, str. 319). Estetsko doživetje in odziv nanj lahko otroka pripelje do tega, da začne ponovno ocenjevati in premišljevati o svojem odnosu, vrednotah, pričakovanjih in se celo sooča s svojimi predsodki, zato je lahko moralno edukativna (Halstead \& Pike, 2006, str. 64, 65). Ker je interdisciplinarna, se s pravo izbiro umetnine (iz katerega koli obdobja) lahko povezuje skoraj z vsemi vsebinami in cilji državljanske vzgoje. P. Hills-Potter je že dokazala, da umetniška dela lahko spodbujajo sodelovanje $\mathrm{v}$ družbi in privzgajajo odnos, potreben za aktivno državljanstvo, še posebej empatijo (citirano v Halstead \& Pike, 2006, str. 66 ).

Halstead in Pike sta sicer za državljansko vzgojo relevantno umetnost našla v grafitih in angleškem slikarstvu 18. stoletja, konkretneje Hogartovo serijo Harlots Progress, ki je močno moralno edukativna. Predlagata, da se ob upodobitvi zgodbe o revni kmetici, ki je v začetku 18. stoletja prišla v London iskat boljšega življenja, postala prostitutka, kmalu umrla za sifilisom, za sabo pa pustila nepreskrbljenega otroka, otroci pogovarjajo o seksualni etiki, zakonu, lokalni avtoriteti, sodobnih oblikah prostitucije, izsiljevanju itd. ter s tem uresničujejo

2 Ta problem sicer presega namen tega članka in verjetno bi nanj najbolje odgovorili filozofi oz. estetiki. Na tem mestu lahko opozorimo le, da sta bila pred razsvetljenstvom glavna podpornika umetnosti Cerkev in plemstvo (ter v manjši meri meščanstvo), ki sta zelo dobro vedela, kaj naročata oz. plačujeta (glej tudi Žerovc, 2011c, str. 13 in Žerovc, 2012, str. 10-12). 
cilje državljanske vzgoje (Halstead \& Pike, 2006, str. 71-74).

Vigotski pravi, da je umetnost prvobitno in najmočnejše orožje v borbi za obstanek, je najpomembnejše stičišče vseh bioloških in socialnih procesov osebnosti v družbi, brez nove umetnosti ne more biti niti novega človeka (Vigotski, 1975, str. 312-327). Kakšna je torej sodobna umetnost in kako se sodobna umetnost povezuje s konceptom aktivnega državljanstva?

Sodobna umetnost se precej razlikuje od svoje predhodnice - moderne umetnosti. Moderna umetnost se je hotela osamosvojiti od ideologij, ni hotela biti ilustrativna, umetniki so se imeli za genije, stvaritelje, izumitelje, edini diktat, ki so se ga držali, pa je bilo iskanje novega in originalnega. Modernisti so se ukvarjali s sliko kot dvodimenzionalno površino, ki je pokrita $\mathrm{z}$ barvami, in niso hoteli, da bi prikazovala kar koli drugega, zato se je moderna umetnost zelo odmaknila od družbe. Sodobnih umetnikov pa ne zanima novo ali napredek, ne zanimajo jih točno določene stilne usmeritve, ampak jim je dovoljen pluralizem idej, materialov in medijev, zato je ena bistvenih vidikov sodobne umetnosti heterogenost. Mnogim sodobnim umetnikom je skupno, da se hočejo približati življenju, družbi, zato so skozi najrazličnejše likovne prakse začeli govoriti o našem vsakdanjem življenju. Predstavitev sodobne umetnosti ni več vezana le na muzeje in galerije, ampak se seli tudi v druge javne prostore, na primer v nakupovalna središča, s tem pa privablja publiko, ki sicer ni v stiku z umetnostjo in nikoli ne bi stopila v umetnostni muzej ali galerijo. Mnogi umetniki bolj kot sami v svojem ateljeju delajo v socialnih in okoljskih situacijah ali v partnerstvu s skupnostmi ali obiskovalci, zato je v ospredje stopila kolektivna estetika. Umetniki svoje dejavnosti nimajo več za vzvišeno dejavnost, ampak svoj poklic primerjajo z drugimi poklici. Tako sodobna umetnost ni več avtonomno, iz življenja izvzeto polje (kot je bilo v modernizmu), ampak območje, ki je vpeto v širši politični, kulturni in družbeni kontekst, se na to vpetost zavestno odziva in je polje za refleksijo in razmislek o kulturnih in družbenih problemih sedanjosti (Krauss, 1988; Groys, 2002, str. 11-22; Weintraub, 2003; Millet, 2004, str. 11-39; Zabel, 2000, str. 261264; Zabel, 2005, str. 6-19). V umetniških delih, kjer publika aktivno sodeluje oz. participira, kjer je publika del umetniškega procesa, ni več pomemben končni produkt, ampak so ta dela najbolj ohranjena v spominih ljudi, ki so sodelovali pri teh delih ali se umetnina dogaja v občutkih ljudi, ki sodelujejo pri teh delih. Taka dela obiskovalci dokončajo s svojo razlago ali pa z realnim delovanjem (Millet, 2004, str. 29-35). Govorimo o relacijski umetnosti (Bourriaud, 2007) oz. o participatornih praksah ali o socialno angažiranih umetniških praksah (Helguera, 2011), ki so se pojavile v devetdesetih letih prejšnjega stoletja. Sodobni umetniki tudi govorijo o tem, da hočejo s svojo umetnostjo spremeniti pogled ljudi na določen problem. Svetovno znani performer Ulay - Uve Laysipen, ki se zadnjih pet 
let intenzivno ukvarja $\mathrm{z}$ vodo in je leta $2012 \mathrm{~s}$ svojim umetniškim delom sodeloval v Mariboru pri projektu Evropska prestolnica kulture, je zapisal: »Moja želja je, da bi podal drugačno idejo, podobo vode. Gre za to, da bi se ljudje zamislili in drugače vrednotili vodo, da bi se sploh počutili povezane z njo« (Pungerčič, 2012). Šejla Kamerić, ki je že večkrat razstavljala v Sloveniji, je v zvezi s svojim mednarodno priznanim delom, ki bo še omenjeno, zapisala: »Moj cilj ni bil, da se najde nesrečnik, ki je tako neumnost pisal po zidu, temveč da se usmeri pozornost na odgovornost tistih, ki pošljejo popolnoma nedorasle ljudi na konfliktna območja reševat življenja« (Megla, 2012). Sašo Sedlaček je v zvezi s svojim projektom Infokalipsa zdaj!, pri katerem je opozarjal na razprodajo javnega frekvenčnega spektra, izjavil: »Ravno pred kratkim smo v parlamentu izvedli akcijo z naslovom Manifest, da poslance poučimo o pravilih lepega vedenja « (Tratnik, 2009, str. 17). ${ }^{3}$

Zaradi svoje pluralnosti sodobna umetnost nudi različna razumevanja in s tem daje zgled za strpnost, spoštovanje in kritično mišljenje. Današnji umetniki so raziskovalci življenja v začetku 21. stoletja in odgovarjajo na različne fenomene vsakdanjega življenja. Fokusirajo se na aktualne socialne, politične ali ekonomske teme, kot so trajnostni razvoj, globalizacija, migracija ali kulturne izmenjave, medtem ko drugi zastavljajo bolj intimna vprašanja o človeških odnosih, spominu, življenju in smrti. Vse to pa so vprašanja, ki zadevajo koncept državljanske vzgoje. Veliko aktualnih problemov, ki zadevajo družbo, pa v učnih načrtih ni zajetih in tudi množični mediji ne poročajo o njih. Če vzamemo za primer diskriminacijo, za katero je Miheljeva pokazala (Mihelj, 2003, str. 20), da se pri predmetu zgodovina $\mathrm{v}$ osnovni šoli o njej sicer govori, a le ob zgledu fašizma in nacizma »okupatorjev«, ne pa o tem, kaj se dogaja zdaj, v času v katerem trenutno živimo. Dobre razmisleke o diskriminaciji tukaj in zdaj pa daje sodobna umetnost, kot bomo videli v nadaljevanju. Sodobna umetnost se namreč odziva na aktualne probleme prej, kot pridejo $\mathrm{v}$ širšo zavest. Zato nam sodobna umetnost pomaga razumeti sedanjost, $\mathrm{v}$ kateri živimo, ponuja nam uvid $\mathrm{v}$ družbeni ustroj, v katerem živimo, in nas spodbuja, da ga sooblikujemo. Te participatorne prakse, pri katerih umetnik sam oblikuje posebne skupnosti, gledalec pa sodeluje pri produkciji umetnine in se umetnina dogaja v njem, $v$ njegovih občutkih, ki jih doživlja ob tem, ko sodeluje, so pravzaprav prvoosebna izkušnja, ki nas pripravlja na to, da lahko razmišljamo o določenem pojavu, ravnanju, stvari, oziroma nas, če participiramo, prisili, da ob nekem dogodku doživljamo občutke, ki so za nas lahko celo travmatični in ki jih lahko kasneje predelamo sami s sabo ali v razgovoru $\mathrm{z}$ drugimi. Sodobne participatorne prakse nam tudi ponujajo, da neko dejanje, ki je moralno sporno, izvršimo na simbolični ravni in to dejanje pripravlja

3 Sašo Sedlaček je bil kot umetnik tudi že angažiran v pedagoškem procesu (Kulturni bazar 2012: Program strokovnega usposabljanja, 2012). 
teren za razmišljanje. Tako smo na primer leta $2000 \mathrm{v}$ Koldingu in leta $2006 \mathrm{v}$ Dornbirnu lahko v kuhinjskem mešalniku zmleli zlato ribico (Žerovc, 2011a, str. 108). Preden smo se lotili tega dejanja, smo morali temeljito razmisliti, ali bomo to storili ali ne in zakaj - razmišljali smo o našem ambivalentnem odnosu do živali. Torej je participatorna praksa že sama po sebi edukativna, saj je zelo podobna pedagoški metodi igre vlog in simulaciji konkretnih življenjskih primerov, ki so priporočljive pri edukaciji za demokratično državljanstvo (Židan, 2004, str. 51, 52; UN DDE, 2011, str. 20). Pri tem pa je treba poudariti, da pri participaciji v sodobni umetnosti ne gre za narejeno, simulirano igro, ampak gre za avtentično, pravo igro vlog, ki je gotovo bolj prepričljiva in učinkovita, kot če le gledaš podobo. V sodobnem svetu morda ni več dovolj, da se ob neki moralno edukacijski podobi pogovarjamo. Te participativne prakse skoraj nikoli niso individualne in so kolektivne, kar že samo po sebi nagovarja udeležence, da po dogodku izmenjujejo občutke in mnenja.

Ker še nimamo metodologije za vrednotenje sodobne umetnosti (Millet, 2004, str. 66), si pri njenem razumevanju oz. pedagoški interpretaciji lahko morda še najbolje pomagamo s poststrukturalističnimi metodami, v katerih se prepletajo različne vede in stroke in ki nam približujejo tudi vprašanja o nas samih (Larcher in Hooper-Greenhill citirano v Tavčar, 2001, str. 26). Torej ob teh pogovorih ne spoznavajo le umetnine, ampak tudi sebe in drug drugega, gojijo razumevanje do stališč in mnenj svojih vrstnikov, kar je tudi cilj državljanske vzgoje. Ko se učenci pogovarjajo o sodobni umetnosti, se pogovarjajo tudi o kontekstu, v katerem je umetnina nastala, o ideji, ki jo nosi umetnina, in o tem, zakaj je nastala, torej o svetu, v katerem živijo in si tako širijo horizont, se sprašujejo in diskutirajo o sodobnih problemih, ki jih imajo sami. Prepoznavajo probleme sodobne družbe, kar je tudi eden izmed ciljev državljanske vzgoje.

$\mathrm{V}$ nadaljevanju poglejmo, kakšni so ti cilji. DDA je obvezen predmet v 7 . in 8. razredu. Analizirala bom cilje tega predmeta in ugotavljala povezljivost $z$ vsebinami, ki jih tematizira sodobna umetnosti. Zato bom cilje primerjala s cilji LV za tretjo triado.

\section{(Ne)povezljivost učnega načrta za likovno vzgojo $\mathrm{z}$ učnim načrtom državljanska in domovinska vzgoja ter etika}

Vsebine sodobnih umetniških praks, ki sem jih navedla zgoraj, se lahko povezujejo z vsemi splošnimi cilji DDE (razvoj politične pismenosti, razvoj kritičnega mišljenja in nekaterih stališč in vrednost ter dejavno vključevanje učencev v družbeno življenje), saj k razvoju le teh prispeva na primer:

- razprava o sobivanju različnih ljudi in družbenih skupin, 
- $\quad$ spremljanje aktualnih družbenih, političnih, ekonomskih in ekoloških vprašanj,

- razprava o etičnih načelih,

- prepoznavanje kršitev človekovih ali otrokovih pravic

in še bi lahko naštevali (UN DDE, 2011). Vsebine sodobnih umetniških praks se najbolj povezujejo z naslednjimi operativnimi cilji za 7. razred:

- $\quad$ razumejo, kako pomembna je za skupnost medsebojna strpnost njenih članov,

- $\quad$ razumejo, kako nastajajo predstave o drugih in drugačnih. V medijskih sporočilih in v vsakdanjem življenju spoznajo stereotipe in predsodke ter razvijajo kritičen odnos do njih. Spoznavajo pomen strpnosti in medsebojnega spoštovanja za kulturno sobivanja,

- $\quad$ razvijajo sposobnost za izražanje stališč

in $\mathrm{z}$ vsemi cilji vsebinskega sklopa Slovenija je utemeljena na človekovih pravicah. $V$ učnem načrtu za 8 . razred se operativni cilji na vsebine sodobnih likovnih praks vežejo $\mathrm{z}$ vsebinskim sklopom Finance, delo in gospodarstvo ter $\mathrm{z}$ vsemi cilji v vsebinskem sklopu Svetovna skupnost.

Sodobna umetnost $\mathrm{v}$ učnem načrtu LV ni zajeta, saj je učni načrt strukturiran na oblikovalski področji, na katerih se učenci učijo likovno izražati. To sta oblikovanje na ploskvi in oblikovanje $\mathrm{v}$ tridimenzionalnem prostoru. Tako na primer niso zajeti izrazni mediji, ki jih uporablja sodobna likovna umetnost niti sodobna umetnost kot taka, saj učni načrt ne vsebuje nobenih umetnostnih obdobij ali slogov. Na neprisotnost sodobne umetnosti in sodobnih izraznih medijev v učnem načrtu že skoraj petnajst let opozarja predvsem T. Zupančič (prej Vrlič) (Vrlič, 1998, 2000, 2001; Vrlič \& Čagran, 2003; Zupančič, 2008; Duh \& Zupančič, 2009), vendar je problem učnega načrta njegova neustrezna konceptualna struktura (Bračun Sova \& Kemperl, 2012). V objavljenih raziskavah in primerih dobrih praks tako T. Zupančič in M. Duh učencem pokažeta tudi dela sodobnih umetnikov. Pri izbiri umetniških del nista povsem dosledna, saj se med njimi pojavljajo tudi dela tipičnih modernistov, na primer Pieta Mondriana (Duh \& Zupančič, 2009; Duh \& Herzog, 2012, str. 25), največkrat izbereta dela tujih umetnikov (dela pokažeta na reprodukcijah), ki jih v naših galerijah in muzejih ni moč videti. ${ }^{4}$ Ko Duh zapiše, da je treba pri izbiri umetnine upoštevati načelo kakovosti (Duh, 2008, str. 103; Duh \& Zupančič, 2009; Duh \& Herzog, 2011, str. 21, 22 ), nehote pomislimo, da umetnine slovenskih umetnikov in umetnine, ki jih predstavljajo slovenske galerije, morda niso dovolj kakovostne.

Med splošnimi cilji UN LV (Učni načrt LV, 2011) lahko najdemo le en cilj, ki bi ga lahko uresničevali s spoznavanjem sodobnih likovnih praks, in

4 Izjema je Zupančičeva raziskava, objavljena leta 2001 (Vrlič, 2001). 
sicer, da »učenci razvijajo občutljivost do likovne kulturne dediščine in kulturne različnosti«. A pravzaprav sodobne likovne prakse sem ne sodijo, saj še niso dediščina. Med operativnimi cilji za tretjo triado pa najdemo:

- $\quad$ ob likovnih delih, likovnih izdelkih učencev ter zgledih iz narave in okolja spoznavajo likovne pojme, povezane z oblikovanjem na ploskvi,

- $\quad$ razvijajo sposobnost analiziranja in vrednotenja likovnih del,

- $\quad$ spoznajo likovna dela nacionalne in mednarodne likovne kulturne dediščine,

- $\quad$ ob likovnih delih, likovnih izdelkih učencev ter zgledih iz narave in okolja spoznavajo likovne pojme, povezane $\mathrm{z}$ oblikovanjem $\mathrm{v}$ prostoru,

- $\quad$ spoznajo pomembna likovno umetniška dela iz različnih oblikovalskih področij, ki pripadajo domači in svetovni kulturni dediščini.

$\mathrm{V}$ tretji in peti cilj spet ne moremo vpeti sodobnih likovnih praks, saj te, kot že rečeno, niso dediščina. Prvi in četrti cilj bi se lahko navezoval tudi na sodobno umetnost, a pri tem cilju se spoznava le likovne pojme, kot na primer kompozicija, nasičena barva, barvna skladnost, zračna perspektiva, horizont, prostorski plani, kiparstvo v arhitekturi, masivna in skeletna gradnja, komponiranje $\mathrm{z}$ dodajanjem. Pri sodobni umetnosti pa je bolj kot forma pomembna vsebina, ideja, koncept. Torej bi spoznavanje in razumevanje sodobne umetnosti lahko umestili le v drugi cilj. Zanimivo, da je med cilji prve triade navedeno tudi, da učenci ob obisku likovnih razstav pridobivajo odprtost do najrazličnejših načinov likovnega ustvarjanja, med cilji druge in tretje triade pa tega cilja ni več. Obisk galerij se ponovno pojavi šele v poglavju Didaktična priporočila. $\mathrm{Na}$ začetku tega poglavja je namreč zapisano: »Učitelj pri likovni vzgoji učence ves čas tudi kulturno vzgaja. Na smiseln način v posamezne korake učnega procesa vključuje primere likovnih del, reprodukcij ali originalov likovnih stvaritev. Za poglobljeno spoznavanje umetniških stvaritev učitelj vsaj enkrat na leto učence pelje na ogled razstave v galerijo ali v muzej, organizira pogovor z umetnikom (tudi v ateljeju) ipd.«V nadaljevanju so didaktična priporočila ločena po triadah, a za tretjo triado obisk galerij in spoznavanje umetnin ni več omenjeno. $\mathrm{Na}$ kakšen način je pravzaprav mišljeno spoznavanje umetnin, pa izvemo iz didaktičnega priporočila za prvo triado: »Smiselno in ustvarjalno jih vgrajuje v posamezne faze učnega procesa kot ponazorilo (učilo) za nazorno spoznavanje likovnih pojmov, spoznavanje posebnosti likovne tehnike ali motiva.« Tu se ponovno pokaže konceptualni problem zasnove učnega načrta (Bračun Sova \& Kemperl, 2012). Prav tako razumevanja umetnin ne najdemo pri preverjanju in ocenjevanju znanja, kar je mogoče pripisati dejstvu, da se sme pri likovni vzgoji ocenjevati le likovne izdelke. Sicer bi tudi skozi učenčev likovni izdelek lahko 
ocenili standard znanja "pojasni pomen kulturne dediščine za slovenski in svetovni prostor«, a pri tem ni jasno, ali to pomeni tudi razumevanje umetnosti in zakaj je v ta UN vključena kar vsa kulturna dediščina in ne le umetnostna.

Analiza pokaže, da se lahko upravičeno vprašamo, ali učenci pri likovni vzgoji v tretji triadi sploh pridejo v stik s sodobnimi likovnimi praksami, če pa pridejo v stik, je vprašanje, na kakšen način jih obravnavajo. $S$ tem pridemo do problema medpredmetnega povezovanja.

UN DDE je z napotki za medpredmetno povezovanje zelo skop, poudarja le, naj bosta kulturna vzgoja in vzgoja za trajnostni razvoj osrednji sestavini predmetnega in medpredmetnega pristopa poučevanja. Prav tako UN LV ne konkretizira vsebin in predmetov, s katerimi je možno povezovanje. Pri opredelitvi predmeta sta sicer kot dve izmed petih ključnih poti za doseganje nalog predmeta likovna vzgoja izpostavljeni »navezovanje problemsko zasnovanih nalog na likovno umetnost in vizualno kulturo « ter "povezava z drugimi predmetnimi področji in z vsakdanjim življenjem«. Sicer pa se povezovanje priporoča na ravni likovnih pojmov: »1. Povezovanje likovnih pojmov s pojmi vsebin iz drugih predmetnih področij, ki temeljijo na besedni, ustni ali pisni interpretaciji. 2. Povezovanje likovnih pojmov s pojmi drugih predmetnih področij, ki temelji na likovni interpretaciji - likovnem izražanju. Načrtovane naloge se izvedejo likovno.« Zapis temelji na strokovnem članku T. Tacol (2002), ki predlaga ta dva načina. Pri razlagi drugega načina pravi, da je izpostavljeni likovni problem v likovni nalogi lahko likovni motiv. To ponazori z motivom konja, pri čemer pa je treba likovno nalogo vseeno povezati z likovnim pojmom, na primer pika, črta, nemešane barve, mešane barve itd. Zapiše tudi, da »medpredmetno povezovanje v smislu samo povzemanja motiva iz vsebin, spoznanih pri drugem predmetnem področju, in realizacija tega motiva $\mathrm{v}$ izbrani likovni tehniki, ni sprejemljivo« (prav tam, str. 46). V vsakem primeru mora biti torej medpredmetno povezovanje na strani likovne vzgoje povezano $\mathrm{z}$ likovnim pojmom, ki je likovno teoretski in v konceptu modernističen, kaže pa se v likovnem izdelku.

Iz analize izhaja, da se ciljev, kot so razvijanje sposobnosti analiziranja in vrednotenja likovnih del ali spoznavanje likovnih del nacionalne in mednarodne likovne kulturne dediščine, sploh ne povezuje, saj jih predlagano medpredmetno povezovanje sploh ne predvideva.

Morda je to razlog, da se pri dnevih dejavnosti v osnovnih šolah tako redko pojavljajo likovne dejavnosti (tako na perceptivni kot na produktivni ravni), kot to ugotavljata M. Duh in J. Herzog (2012). Najverjetneje je tudi zato objavljenih idej, kako povezovati likovno vzgojo z državljansko vzgojo, tako malo, pa še te, ki obstajajo, so vezane le na eno temo, in sicer na okoljevarstvo, 
znotraj tega večinoma na problematiko odpadne embalaže, glavni dokaz za ponotranjanje ekološke problematike pa je likovni izdelek učenca (Zupančič, 2009; Duh \& Herzog, 2011; Duh \& Herzog, 2012).5 Ustvarjanje iz odpadnih materialov pravzaprav tudi ne kaže na srž problema odpadkov, ampak predvsem podpira ideologijo recikliranja. Velikokrat namreč odpadke reciklirajo ista podjetja, ki odpadke zavestno proizvajajo, s tem pa si ustvarjajo le še večji dobiček. Velika evropska in ameriška podjetja strupene odpadke izvažajo v afriške države, kjer ljudje zaradi tega celo umirajo, kot to kažejo tudi Greenpeaceove raziskave (Omladič, 2011, str. 12-14).

Bolj poglobljeno s stališča okoljevarstva se je raziskave o likovni vzgoji in ekologiji lotil B. Flajšman (2009), ki je skušal uravnotežiti razmerje med sporočilnostjo in likovno-formalnimi pojmi. V raziskavi je učencem pokazal 10 likovnih del z ekološko sporočilnostjo, ob katerih so morali učenci sami napisati, kaj dela predstavljajo in sporočajo. Zanimivo je, da je bilo med temi deli kar osem plakatov oz. razglednic, ki imajo precej jasno sporočilnost, saj je to ena glavnih zahtev dobrega plakata. Le dve izmed desetih del sta bili umetniški deli, ki sta bili prikazani na reprodukcijah, oba avtorja pa sta Američana. Zanimivo je tudi, da se je avtor odločil raziskavo delati v 9. razredu, saj v okviru medpredmetnega povezovanja teh tem ni mogel povezati s predmetom Državljanska vzgoja in etika. V tistem času je bila okoljska problematika pri tem predmetu umeščena v 8. razred (Učni načrt Državljanska vzgoja in etika, str. 32).

Zelo zanimivo je, da nihče od omenjenih avtorjev učencev ni seznanil z umetniškimi deli slovenske skupine OHO, katere člani so se prvi v našem prostoru začeli ukvarjati z okoljevarstvenimi vprašanji. Ti so v času prehajanja v tretjo fazo (leta 1969) izvajali landart projekte, a veliko manj invazivne kot njihovi ameriški kolegi ter že vnaprej namenjene temu, da jih čas hitro zabriše (Kočevar, 2009, str. 150). Ekološka vprašanja so bila glavna tema tudi kasnejšega samostojnega delovanja Marka Pogačnika v Šempasu (Ravnikar, 2009, str. 32), svetovno priznane slovenske umetnice Marjetice Potrč (Ravnikar, 2009, str. 32; Vovk, 2009, str. 70-76), Sašo Sedlaček, eden najpomembnejših slovenskih sodobnih umetnikov, ki je že bil in bo še omenjen, pa se prav tako že več kot deset let ukvarja prav z okoljevarstvenimi problemi, zlasti odpadki in recikliranjem (Grafenauer, 2011). Za vse tri bi zelo težko zapisali, da niso dovolj kakovostni (če vzamemo Duhovo merilo izbire), saj je imel Marko Pogačnik leta $2012 \mathrm{v}$ Moderni galeriji v Ljubljani obsežno retrospektivno razstavo $\mathrm{z}$ naslovom Umetnost življenja - življenje umetnosti, v času pisanja tega prispevka pa je na temo zdravljenja zemlje z litopunkturo predaval na sedežu Unesca v Parizu (M. K., 2012). Marjetica Potrč se je leta 2011 uvrstila na prestižno tretje mesto na lestvici

5 Pri tem je spet treba opozoriti na nedoslednost pri izbiti umetnikov. 
desetih najpomembnejših sodobnih umetnikov na svetu, ki jo objavi ameriški tednik Newsweek. Pri utemeljitvi so poudarili prav njeno socialno angažirano umetnost v favelah južne Amerike. ${ }^{6}$ Sašo Sedlaček je prejemnik več domačih in tujih nagrad, med njimi je leta 2006 prejel slovensko nagrado OHO, leta 2012 pa je bil nominiran za Henkel Art.Award., nagrado za umetnike iz Srednje in Vzhodne Evrope (T. C., 2012). Leta 2011 je imel samostojno pregledno razstavo v Koroški galeriji likovnih umetnosti v Slovenj Gradcu, ki se je leta 2012 ponovila še v Jakopičevi galeriji v Ljubljani.

\section{Trije primeri: proletarier aller länder, žicar, eu/others}

Za ponazoritev možnega povezovanja sodobnih likovnih praks in državljanske vzgoje vzemimo le en splošni cilj učnega načrta DDE, in sicer presoja stereotipnih predstav o drugih in drugačnih. Pri izbiri cilja sem izhajala tudi iz ugotovitve raziskovalcev v projektu Primerjalna raziskava državljanskega izobraževanja in vzgoje - cep (raziskava, ki je potekala leta 1999, je zajela učence iz 28 držav), ki pravi, da imajo slovenski učenci do priseljencev pomembno manj naklonjen odnos, kar po mnenju raziskovalcev vzbuja skrb in terja nadaljnje analize (Pedagoški inštitut, 2002). ${ }^{7}$

Umetnost je $\mathrm{v}$ preteklosti lahko tudi sama generirala predsodke. Tako na primer ob reliefni upodobitvi timpanona portala cerkve sv. Magdalene v Vézelayu iz leta 1130 lahko razmišljamo in se pogovarjamo o diskriminaciji oz. odnosu do drugega. Upodobitev kaže Kristusa, ki naroča apostolom, naj širijo krščansko vero po vsem svetu. Na prekladi portala so upodobljeni tisti ljudje, ki misije širjenja vere še niso sprejeli in so upodobljeni kot "polljudje« - nekateri imajo prašičje rilce, drugi slonja ušesa, spet tretji so pritlikavci. Gre torej za utrditev podobe o nevernikih $\mathrm{v}$ času križarskih pohodov, pri katerih je cerkev imela pomembno vlogo.

A veliko sodobnih umetnikov se tega problema loteva na drugačen način, saj se ukvarjajo s tem, kako stereotipne predstave o drugih spremeniti. Za ponazoritev bom med njimi izbrala le tri umetnike, njihove umetnine oz. umetniške dogodke, ki smo jih v Ljubljani lahko videli v zadnjem desetletju. Izhajam namreč iz prepričanja, da je stik z originalnimi umetniškimi deli ključnega pomena za vse, ki proučujejo, razmišljajo ali se ukvarjajo in ustvarjajo

6 Umetnica je med drugim sodelovala na Beneškem bienalu, bienalu v San Paulu in na razstavi Skulptur-Projekte v Münstru. Leta 2000 je dobila prestižno mednarodno nagrado za sodobno umetnost, nagrado Hugo Boss, ki je vključevala tudi osebno razstavo v Guggenheimovem muzeju v New Yorku (Gopnik, 2011).

7 V drugi mednarodno primerjalni študiji, ki je bila opravljena deset let kasneje (2009), sicer slovenski učenci niso več odstopali v negativni smeri in so se uvrstili v mednarodno povprečje (Šimenc, 2012, str. 96). 
umetnost (Charman, Rose, \& Wilson, 2006; Talboys, 2010). To prav gotovo še toliko bolj velja za participatorne likovne prakse, saj se umetnina, kot sem že napisala, dogaja v nas in umetniškega dogodka preko reprodukcije sploh ne moremo doživeti. Ob umetninah, ki so sicer večpomenske in mnogoplastne, bom izpostavila le tisti del vsebine, ki je povezan z omenjenim splošnim ciljem. Jeseni leta 2011 smo na 29. ljubljanskem grafičnem bienalu, ki je bil posvečen umetniškemu dogodku, lahko participirali pri umetnini umetnika turškega rodu, Serkana Őzkaya, ki živi in dela v New Yorku in Istanbulu. V instalaciji z naslovom Proletarier aller Länder (Proletarci vseh dežel) so bili na tla galerije prilepljeni tisoči majhnih figur delavcev iz rdeče plastične pene $\mathrm{Z}$ značilno delavsko dvignjeno roko, stisnjeno v pest (Žerovc, 2011b, str. 142, 143). Figurice so bile po prostoru razporejene tako na gosto, da se obiskovalec ni mogel izogniti stopanju po figuricah, če je hotel napredovati v naslednjo dvorano galerije. Obiskovalec se je tako po delavskem razredu sprehodil nalahno, ali pa je dolgo skakal po njem, saj so se prilepljene figurice iz prožne pene vsakokrat postavile nazaj na noge. A ob koncu razstave so nekateri delavci le »klonili« pod težo tistih, ki so jih tlačili k tlom. Ta postavitev je nekatere obiskovalce tako pretresla, da se niti niso odločili, da bi stopili v naslednjo dvorano, ker jim je bilo tudi na simbolni ravni preveč težko tlačiti delavca. Drugi so po figuricah stopali nalahno, kot bi stopali bosi po steklu, nekateri pa so prav uživali v skakanju. Umetnik nas je tako na sicer precej duhovit način napeljal na možnost, da razmišljamo o problematiki sodobnega proletariata in njihovega mesta v družbi.

Drugo umetniško delo je Žicar Saša Sedlačka, ki se je leta 2006 sprehajal po ljubljanskem City parku, po ulicah Tokia in Tajpeja, leto kasneje so ga uporabljali ljubljanski brezdomci, lani pa smo ga lahko videli na retrospektivni razstavi v Ljubljani. Glavne teme Saša Sedlačka, ki velja za eno osrednjih imen sodobne umetnosti na Slovenskem, so odpadki, recikliranje in odnos do drugega v globaliziranem svetu. Na probleme sodobne družbe ne le opozarja, ampak ponuja tudi (umetniške) rešitve. Za Žicarja je prejel več nagrad v tujini, pa tudi slovensko nagrado OHO (Tratnik, 2009; Grafenauer, 2011). Žicar je robot, sestavljen iz odpadne računalniške tehnologije. Leta 2006 je v polomljeni slovenščini v City parku, kjer socialno ogroženim sicer ni dovoljeno prosjačiti, mimoidoče prosil za denar. Robot je bil pri zbiranju denarja zelo uspešen, saj je na uro zbral več kot 1.000 takratnih slovenskih tolarjev. Projekt je pokazal, da veliko raje kot $\mathrm{v}$ človeško dlan damo $\mathrm{v}$ integrirana vezja, robotu smo plačali za zabavo, užitek, ki nam ga ponuja njegova tehnologizirana človeškost. Žicar je bil posebej privlačen za mamice $z$ majhnimi otroki, ki pa se po navadi klošarjem izogibajo. Podobna je bila reakcija prebivalcev Tajpeja. Tam je bil Žicar, ki je kmalu pritegnil pozornost mnogih mimoidočih, postavljen poleg berača, ki 
je ostal osamljen. Po prihodu policista je moral berač oditi, robot pa je lahko ostal (Grafenauer, 2011, str. 30-33).

V okviru mednarodnega bienala za sodobno umetnost Manifesta, ki se je leta 2000 odvijal v Ljubljani pod naslovom Borderline sindrom, je Šejla Kamerić izvedla instalacijo EU/Others. Rojena Sarajevčanka je mednarodno prepoznavna postala $\mathrm{z}$ delom iz leta 2003, ki prikazuje Kamerićevo sámo, ko gleda gledalca, preko njene podobe pa je reproduciran grafit, ki ga je mirovni vojak Združenih narodov napisal v Srebrenici na steno kasarne, s čimer je hotela opozoriti na predsodke do drugih ljudi in potrebo, da se jih osvobodimo. $\mathrm{V}$ Ljubljani je na Tromostovju dala namestiti napise, ki se bili v tistem obdobju sestavni del mej evropske unije: EU citizens in Others. Danes za Others uporabljamo bolj korekten napis Non european citizens. Takrat pa je bil za umetnico, kot sama pravi, to popoln šok, saj je kot državljanka Bosne in Hercegovine takrat brez vizuma lahko potovala le $\mathrm{v}$ peščico držav. To je pri njej sprožilo vprašanje identitete, kdo so ti »drugi« in kaj kot »druga« počne na evropskem bienalu sodobne umetnosti v Ljubljani. V času instalacije smo namreč tudi državljani Slovenije na evropskih mejah imeli status »drugih» (Kamerić, 2000).

Že samo ti trije primeri potrjujejo Vigotskijevo tezo, da »nova« umetnost daje ogromno priložnosti za »novega « človeka. Povedano drugače z vidika današnjih okoliščin: sodobna umetnost nam lahko kaže pot naprej, pot iz krize (okoljske, medosebne, krize vrednot itd.). Sodobno umetnost je treba le spremljati, jo razumeti in doživljati.

\section{Zaključek}

Če se bo koncept aktivnega državljanstva v prihodnosti prilagajal globaliziranemu in multikulturnemu svetu, če se bo ukvarjal z ekonomsko, politično in socialno neenakostjo ne le znotraj nacionalne države, ampak med državami, pri čemer bodo eden izmed etičnih temeljev univerzalne človekove pravice, to se pravi vzgoja za globalno državljanstvo (Židan, 2007, str. 14; Demaine, 2010; Davies \& Evans Ried, 2010, str. 217), potem bo poznavanje, razumevanje in doživljanje sodobne umetnosti še kako aktualno oz. potrebno. Analiza je pokazala, da preko spoznavanja vsebin sodobne umetnosti lahko uresničujemo cilje aktivnega državljanstva. Namreč edino sodobna umetnost res prepoznava in opozarja na res aktualne probleme, na probleme, o katerih množični mediji ne poročajo. Probleme prepoznavajo, ko so šele v nastajanju in že predvidevajo posledice. Sedlačkova akcija Just do it!, v kateri je leta 2003 zazidal vhod v ljubljanski City park z zidaki, narejenimi iz reklamnih oglasov, pri čemer je tematiziral tako potrošništvo kot odpadke in reciklažo, je nastala, ko je bila Slovenija na 
višku potrošništva in smo bili večinoma še vsi navdušeni nad obilnim reklamnim materialom, s katerim so trgovci zasipavali naše nabiralnike (Grafenauer, 2011, str. 24-26). Šejla Kamerić je s svojo že omenjeno podobo Bosansko dekle polepila stene Sarajeva precej prej, preden je mednarodna skupnost prepoznala, da se je v Srebrenici zgodil genocid nad Bošnjaki (Megla, 2012, str. 24, 25)

Integriranje sodobne umetnosti v kurikulum - tako zasnovani kurikulum, kot je zdaj - se zdi problematično, saj moramo sodobno umetnost doživljati tukaj in zdaj, če hočemo, da bo imela željen učinek. Uvajanje sodobne umetnosti v aktualni kurikulum namreč nujno vodi v to, da sodobna umetnost zaradi časovne distance izgubi svojo aktualnost. Potreben je torej drugačen koncept kurikuluma, na kar je že bilo opozorjeno (Bračun Sova \& Kemperl, 2012).

Zelo pomembno je, da imajo učenci čim več avtentičnega stika s sodobno umetnostjo in da pri tem pedagogi uporabljajo sodobne metode za doživljanje in razumevanje umetnin. Sodobna umetnost se namreč težje kot starejša umetnost poučuje v razredu, saj se umetniškega dogodka, v katerem aktivno participiraš, ne da doživeti na reprodukciji. Zato bi moralo biti v učnem načrtu veliko bolj poudarjeno obiskovanje galerij, muzejev in drugih prostorov, kjer se prezentira sodobna umetnost in odvijajo umetniški dogodki in kjer se bodo učenci lahko na avtentičen način učili aktivnega državljanstva. S tem bi pridobila oba predmeta, tako likovna vzgoja kot državljanska in domovinska vzgoja ter etika. Za to pa bi bilo treba spremeniti koncept medpredmetnega povezovanja likovne vzgoje $\mathrm{z}$ drugimi predmeti.

Podlago za pogostejši neposreden stik s sodobno umetnostjo najdemo v Beli knjigi, kjer je zapisano načelo sodelovanja šole z okoljem, torej se sodelovanje šole $\mathrm{z}$ muzeji in galerijami predvideva eksplicitno (Bela knjiga, 2011, str. 114-117). Z vidika medinstitucionalnega povezovanja pa se zastavlja vprašanje usposobljenosti likovnih pedagogov na eni in muzejskih pedagogov na drugi strani. Tu bi pričakovali, da se bodo galerije in muzeji, ki predstavljajo sodobno umetnost, bolj potrudili k privabljanju šolskih skupin, za učitelje pripravili gradiva o umetninah, umetnikih in s šolskimi kurikulumi povezanih vsebinah ter učitelje vpeljevali v nove in drugačne metode dela, ki spodbujajo interdisciplinarnost. Poleg umetnika namreč le kustos, ki pripravlja razstavo, najbolje pozna umetniško delo, ki se dogaja tukaj in zdaj, saj umetniki še niso valorizirani in zato tudi še ni virov, s katerimi bi si učitelj pomagal, prav tako še ni dostopnih reprodukcij. A kustosi sodobne umetnosti se pri nas te pedagoške vloge premalo zavedajo.

Odgovornost osnovnošolske edukacije pa bi morala biti tudi, da opremi otroke $\mathrm{z}$ orodji, s katerim bodo presojali in se spopadali $\mathrm{z}$ vizualnimi podobami, ki jih je v svetu precej več, kot kdaj koli prej (Knight, 2010, str. 238). 
Zato moramo razmisliti, ali želimo, da nam otroke vzgajajo produkti popularne kulture hollywoodske provenience, ki še vedno podpirajo ideologijo prevlade belega moškega (na primer družinski film Marmaduke iz leta 2010 in drugi Disney produkti, ki jih analizirata Dorfman in Mattelart (2007)), ali pa bi se o aktualnih družbenih problemih in o svetu, v katerem živimo, z njimi raje pogovarjali ob sodobni umetnosti in s tem skušali spremeniti stereotipne predstave tako o drugih kot o nas. $\mathrm{V}$ tem pogledu je, kot je pred desetletjem za angleško edukacijo ugotavljal Pike (2002), potencial umetnosti tudi pri nas še povsem neizkoriščen.

\section{Literatura}

Bela knjiga o vzgoji in izobraževanju v Republiki Sloveniji (2011). Ljubljana: Zavod RS za šolstvo. Bourriaud, N. (2007). Relacijska estetika. Postprodukcija: kultura kot scenarij: kako umetnost reprogramira sodobni svet. Ljubljana: Maska.

Bračun Sova, R., \& Kemperl, M. (2012). The Curricular Reform of Art Education in Primary School in Slovenia in Terms of Certain Components of the European Competence of Cultural Awareness and Expression. Ceps Journal, 2(2), 71-90.

Charman, H., \& Ross, M. (2002). Contemporary Art and the Role of Interpretation. Tate Papers, Autumn 2004. Pridobljeno 15. oktobra 2012, http://www.tate.org.uk/research/tateresearch/ tatepapers/o4autumn/charman.htm

Charman, H., Rose, K., \& Wilson, G. (ur.) (2006). The Art Gallery Handbook: A Resource for Teachers. London: Tate Publishing.

Davies, I. (2003). Državljanska vzgoja in poučevanje in učenje zgodovine. V J. Justin \& M. Sardoč (ur.), Državljanska vzgoja pri pouku zgodovine, geografije in slovenščine (str. 45-62). Ljubljana: I2. Davies, I., Evans, M., \& Reid, A. (2010). Globalizacija državljanske vzgoje? V J. Pikalo (ur.), Državljanstvo in globalizacija: $k$ državljanski vzgoji za sodobni svet (str. 207-238). Ljubljana: Sophia. Demaine, J. (2010). Globalizacija in državljanska vzgoja. V J. Pikalo (ur.), Državljanstvo in globalizacija: $k$ državljanski vzgoji za sodobni svet (str. 147-164). Ljubljana: Sophia.

Devjak, T. (2007). Nadgraditev ciljev predmeta državljanska vzgoja in etika v določenih orientacijah medpredmetnega in praktičnega življenja v šoli. V J. Krek idr. (ur.), Učitelj v vlogi raziskovalca: akcijsko raziskovanje na področjih medpredmetnega povezovanja in vzgojne zasnove v javni šoli (str. 150-178). Ljubljana: Pedagoška fakulteta.

Dobbs, S. M. (1998). Learning in and through Art: A Guide to Discipline-Based Art Education. Los Angeles: The Getty Education Institute for the Arts.

Dorfman, A., \& Mattelart, A. (2007). Kako brati Jaka Racmana. Imperialistična ideologija v Disneyjevih stripih. Ljubljana: Maska.

Drake, S. M. (1998). Creating Integrated Curriculum. California: Corwin Press.

Duh, M. (2008). Likovna vzgoja v funkciji razvijanja ekološke zavesti otrok in mladostnikov. V 
M. Duh (ur.), Razvojno-raziskovalni koncepti ekologije od vrtca do fakultete in naprej v prakso (str. 95-114). Maribor: Pedagoška fakulteta; Rakičan: RIS Dvorec.

Duh, M., \& Zupančič, T. (2009). Sodobna likovna umetnost v kurikulu vrtca. Ljubljana: Zavod Republike Slovenije za šolstvo.

Duh, M., \& Herzog, J. (2011). Ekoart in likovnopedagoška praksa. V M. Duh (ur.), Raziskovalni vidiki ekologije v kontekstu edukacije (str. 17-32). Maribor: Pedagoška fakulteta Maribor, RIS dvorec Rakičan.

Duh, M., \& Herzog, J. (2012). Likovno-ekološki dan. V M. Duh (ur.), Ekološka in etična zavest skozi edukacijski odnos do družbe in narave (str. 14-29). Maribor: Pedagoška fakulteta Maribor, RIS dvorec Rakičan.

Erjavec, A. (1996). K podobi. Ljubljana: Zveza kulturnih organizacij Slovenije.

Flajšman, B. (2009). Likovna dejavnost in ekološko osveščanje. Ljubljana: Debora.

Freedman, K. (2003). Teaching Visual Culture: Curriculum, Aesthetics and the Social Life of Art. New York: Teachers College Press; Reston: National Art Education Association.

Germ, T. (2008). Koordinatorji kulturne ali koordinatorji umetnostne vzgoje? V N. Požar Matijašič \& N. Bucik (ur.), Kultura in umetnost v izobraževanju - popotnica 21. stoletja (str. 39-46). Ljubljana: Pedagoški inštitut.

Gopnik, B. (2011). The 10 Most Important Artists of Today. Art Beast, 5. Junij. Pridobljeno 15. oktobra 2012, http://www.thedailybeast.com/newsweek/2011/06/05/the-10-most-important-artists-of-today. item-3.html

Grafenauer, P. (2011). Velika prostovoljna čistilna akcija: Sašo Sedlaček! V Sašo Sedlaček: Supertrash (str. 22-46). Ljubljana: Aksioma; Slovenj Gradec: Koroška galerija likovnih umetnosti.

Grierson, E. (2003). Framing the arts in education: what is really at stake? V E. Grierson idr. (ur.), The Arts in Education: critical perspectives from Aotearoa New Zealand (str. 93-118). Palmerston North: Dunmore Press.

Groys, B. (2002). Teorija sodobne umetnosti: Izbrani eseji. Ljubljana: Študentska založba.

Halstead, J. M., \& Pike, M. A. (2006). Citizenship and Moral Education: Values in action. London: Routledge.

Helguera, P. (2011). Education for socially engaged art: a materials and techniques handbook. New York: Jorge Pinto Books.

Hickman, R. (2005). Introduction. V R. Hickman (ur.), Critical Studies in Art and Design Education (str. 15-18). Bristol in Portland: Intellect.

Hickman, R., \& Kiss, L. (2010). Cross-Curricular Gallery Learning: A Phenomenological Case Study. International Journal of Art \& Design Education, 29(1), 27-36.

Justin, J. (2003). Didaktično besedilo, pretekli dogodki, današnji državljani. V J. Justin \& M. Sardoč (ur.), Državljanska vzgoja pri pouku zgodovine, geografije in slovenščine (str. 123-138). Ljubljana: I2. Kamerić, Š. (2000). Pridobljeno 15. oktobra 2012, http://www.sejlakameric.com/art/eu_others_text. htm

Karba, P. (2008). Opolnomočenje učencev za življenje etično aktivnih državljanov. Vzgoja in 
izobraževanje: revija za teoretična in praktična vprašanja vzgojno izobraževalnega dela, 39(6), 6-7.

Knight, L. (2010). Why a Child Needs a critical Eye, and Why the Classroom is Central in

Developing it. The International Journal of Art \& Design Education, 29(3), 236-243.

Kočevar, M. (2009). Landart. V N. Zgonik (ur.), Pojmovnik slovenske umetnosti po letu 1945: pojmi, gibanja, skupine, težnje (str. 148-152). Ljubljana: Študentska založba, Inštitut ALUO.

Kostrevc, R. (2006). Državljanska in domovinska vzgoja - občutljiva in pomembna. V A. Barle Lakota \& E. Rustja (ur.), Državljanska in domovinska vzgoja (str. 146-153). Slovenska Bistrica: Beja. Krauss, R. (1988). The Originality of the Avant-Garde and Other Modernist Myths. Cambridge, London: MIT Press.

Kulturni bazar 2012: Program strokovnega usposabljanja (2012). Ljubljana: Ministrstvo za kulturo, Ministrstvo za šolstvo in šport, Ministrstvo za okolje in prostor, Zavod RS za šolstvo. Pridobljeno 15. oktobra 2012, http://www.arhiv.mk.gov.si/si/splosno/vstopna_stran/dogodki/kulturna_vzgoja_in_ kulturni_bazar/

Kunaver, V. (2006). Predmeta državljanska vzgoja in etika ter državljanska kultura v osnovni in srednji šoli ter njuna povezanost s predmetom zgodovina. V A. Barle Lakota \& E. Rustja (ur.), Državljanska in domovinska vzgoja (str. 142-145). Slovenska Bistrica: Beja.

Kymlicka, W. (1999). Education for Citizenship. The School Field: International Journal of Theory and research in education, 10(1-2), 9-36.

M. K. (2012). Marko Pogačnik v Parizu o Zemlji in našem odnosu do nje. Pridobljeno 26. oktobra 2012, http://www.rtvslo.si/kultura/drugo/marko-pogacnik-v-parizu-o-zemlji-in-nasem-odnosu-donje/294365

Megla, M. (2012). Šejla Kamerić, vizualna umetnica: Umetnost ni samo za privilegirane. Delo, sobota, 5. maj 2012, 24, 25.

Mihelj, S. (2003). Povezave učnega načrta državljanske vzgoje in etike z učnimi načrti slovenščine, zgodovine in geografije. V J. Justin \& M. Sardoč (ur.), Državljanska vzgoja pri pouku zgodovine, geografije in slovenščine (str. 19-23). Ljubljana: I2.

Millet, C. (2004). Suvremena umjetnost. Zagreb: Muzej suvremene umjetnosti.

Omladič, L. (2011). Piknik na smetišču. V Sašo Sedlaček: Supertrash (str. 6-20). Ljubljana: Aksioma; Slovenj Gradec: Koroška galerija likovnih umetnosti.

Pedagoški inštitut. (2002). Primerjalna raziskava državljanskega izobraževanja in vzgoje - cep. Pridobljeno 15. oktobra 2012, http://www.pei.si/Sifranti/ResearchProject.aspx?id=16 Pikalo, J. (2010). Predgovor: Državljanska vzgoja za sodobni svet. V J. Pikalo (ur.), Državljanstvo in globalizacija: $k$ državljanski vzgoji za sodobni svet (str. VII-IX). Ljubljana: Sophia. Pungerčič, B. (2012). Ulay - Uve Laysipen: »Deliti z drugimi in skrbeti tudi zanje, ne samo zase«. Pridobljeno 15. oktobra 2012, http://www.zivljenjenadotik.si/info/tekst/prikaz/article/ulay-uvelaysipen-deliti-z-drugimi-in-skrbeti-tudi-zanje-ne-samo-zase/ Ravnikar, B. (2009). Ekologija in umetnost. V N. Zgonik (ur.), Pojmovnik slovenske umetnosti po letu 1945: pojmi, gibanja, skupine, težnje (str. 28-32). Ljubljana: Študentska založba, inštitut ALUO.

Rawding, M., \& Wall, B. (1991). Art and religion in the classroom: a report on a cross-curricular 
experiment. International Journal of Art \& Design Education, 10(3), 293-306.

Resnik Planinc, T. (2003). Državljanska vzgoja in etika z vidika geografije. V J. Justin \& M. Sardoč (ur.), Državljanska vzgoja pri pouku zgodovine, geografije in slovenščine (str. 97-86). Ljubljana: I2. Slater, F. (2003). Vrednote in vzgoja o vrednotah v učnem načrtu geografije v odnosu do koncepta državljanstva. V J. Justin \& M. Sardoč (ur.), Državljanska vzgoja pri pouku zgodovine, geografije in slovenščine (str. 87-108). Ljubljana: I2.

Stibbs, A. (1998). »Language in art and art in language«. Journal of Art and Design Education, 17(2), 201-209.

Šimenc, M. (ur.) (2012). Razvoj državljanske vzgoje v republiki Sloveniji: Konceptualni okvir in razvoj kurikulumov. Ljubljana: Pedagoški inštitut. Pridobljeno 5. februarja 2013, http://www.pei. si/UserFilesUpload/file/digitalna_knjiznica/Dissertationes_22_ISBN_978-961-270-147-5_SWF/ ISBN_978-961-270-147-5.html

Štemberger, V. (2007). Načrtovanje in izvajanje medpredmetnih povezav. V J. Krek idr. (ur.), Učitelj $\mathrm{v}$ vlogi raziskovalca: akcijsko raziskovanje na področjih medpredmetnega povezovanja in vzgojne zasnove v javni šoli (str. 93-111). Ljubljana: Pedagoška fakulteta.

T. C. (2012). Sašo Sedlaček med finalisti za Henklovo nagrado. Delo, 3. 7. 2012. Pridobljeno 15. oktobra 2012, http://www.delo.si/kultura/dediscina/saso-sedlacek-med-finalisti-za-henklovo-nagrado.html Tacol, T. (2002). Problemski pouk likovne vzgoje in medpredmetno povezovanje v novem kurikulumu. Sodobna pedagogika, (2), 40-49.

Talboys, G. K. (2010). Using museums as an educational resource: An Intorductory Handbook for Students and Teachers. Farnham in Burlington, VT: Ashgate.

Tavčar, L. (2001). Otroci, mladostniki in odrasli v galeriji. Priročnik za kustose pedagoge, učitelje, vzgojitelje in starše. Ljubljana: Narodna galerija.

Tavčar, L. (2009). Homo spectator. Uvod v muzejsko pedagogiko. Ljubljana: Pedagoški inštitut. Pridobljeno 11. januarja 2013, http://www.pei.si/UserFilesUpload/file/digitalna_knjiznica/

Dissertationes_3/index.html

Tratnik, P. (2009). Brkljanje, ki sproti rešuje probleme. Maska: Časopis za scenske umetnosti, XXIV, 119-120.

Učni načrt: program osnovna šola: državljanska vzgoja in etika (1999). Ljubljana: Ministrstvo za šolstvo in šport, Zavod RS za šolstvo.

Učni načrt: program osnovna šola: likovna vzgoja (2011). Ljubljana: Ministrstvo za šolstvo in šport, Zavod RS za šolstvo.

Učni načrt: program osnovna šola: državljanska in domovinska vzgoja ter etika (2011). Ljubljana: Ministrstvo za šolstvo in šport, Zavod RS za šolstvo.

Vigotski, L. S. (1975). Psihologija umetnosti. Beograd: Nolit.

Vovk, M. (2009). Utopične vizije, paralelne strategije, privilegirane taktike: trije primeri angažiranih praks v sodobni slovenski umetnosti - Tadej Pogačar, Marjetica Potrč, Franc Purg \& Sara Heitlinger. V T. Vignjević (ur.), Interpretacije vizualnosti: Študije o sodobni slovenski likovni umetnosti (str. 61-83). Koper: Založba Annales. 
Vrlič, T. (1998). Sodobna likovna umetnost pri likovni vzgoji. Likovna vzgoja, (7-8), 21-24.

Vrlič, T. (2000). Smeri razvoja sodobnega predmeta likovna vzgoja. Likovna vzgoja, (11-12), 11-19.

Vrlič, T. (2001). Sodobna umetnost in likovnovzgojna praksa. Likovna vzgoja, (16-17), 16-23.

Vrlič, T., \& Čagran, B. (2003). Empirično uvajanje sodobnih vsebin v likovno vzgojo v osnovni šoli.

Sodobna pedagogika, (4), 126-142.

Weintraub, L. (2003). Making contemporary art: How today's artists think and work. London: Thames \& Hudson.

Zabel, I. (200o). Manifesta 3: Poročilo. Zbornik za umetnostno zgodovino, n. v., 36, 261-294.

Zabel, I. (2005). Sodobna umetnost. V I. Španjol \& I. Zabel (ur.), 95-05. Teritoriji, identitete, mreže: Slovenska umetnost 1995 - 2005 (str. 6-19). Ljubljana: Moderna galerija 2005.

Zupančič, T. (2008). Likovni kurikul - primerjava konceptov v luči prenove učnega načrta za likovno vzgojo. Revija za elementarno izobraževanje, 1(3-4), 33-44.

Zupančič, T. (2009). Ekologija kot primarni cilj likovne vzgoje? Primerjava osnovnih usmeritev finskega in slovenskega likovnega kurikuluma. V M. Duh (ur.), Edukacija za trajnostni razvoj (str. 81-96). Maribor: Pedagoška fakulteta Maribor, RIS dvorec Rakičan.

Žerovc, B. (2011a). Marko Evaristti. V P. Kisin \& B. Žerovc (ur.), Dogodek. The Event, 29. Grafični bienale. The 29th Biennal of Grafic Arts. 23. september-20. november 2011 (str. 108). Ljubljana:

Mednarodni grafični center.

Žerovc, B. (2011b). Serkan Özkaya. V P. Kisin \& B. Žerovc (ur.), Dogodek. The Event, 29. Grafični bienale. The 29th Biennal of Grafic Arts. 23. september-20. november 2011 (str. 142,143). Ljubljana:

Mednarodni grafični center.

Žerovc, B. (2011c). O umetniškem dogodku na umetnostnem dogodku. V P. Kisin \& B. Žerovc (ur.), Dogodek. The Event, 29. Grafični bienale. The 29th Biennal of Grafic Arts. 23. september-2o. november 2011 (str. 13-21). Ljubljana: Mednarodni grafični center.

Žerovc, B. (2012). Zakaj na likovnem področju razmišljati o umetniških dogodkih? Maska: Časopis za scenske umetnosti, XXVII(147-148), 10-15.

Židan, A. (2004). Za kakovostnejša družboslovna znanja: didaktični in znanstveni prispevki. Ljubljana: Fakulteta za družbene vede.

Židan, A. (2007). Vzgoja za evropsko demokracijo. Ljubljana: Fakulteta za družbene vede. 


\section{Biografski podatki}

MetOdA KeMPERL, doktorica umetnostnozgodovinskih znanosti, izr. prof. za umetnostno zgodovino, zaposlena na Univerzi v Ljubljani, Pedagoški fakulteti, oddelek za likovno pedagogiko. Članica programske skupine Slovenska umetnost in umetnost Srednje Evrope in Jadrana. Soustanoviteljica Slovenskega društva za preučevanje 18. stoletja. Dobitnica priznanja Izidorja Cankarja za posebne dosežke v umetnostni zgodovini, ki ga podeljuje Slovensko umetnostnozgodovinsko društvo. Soavtorica in koordinatorica novega 2. stopenjskega študijskega programa Muzejska pedagogika. Glavna področja raziskovanja: baročna umetnost, baročna arhitektura, baročna kulturna zgodovina, muzejska pedagogika. 